\title{
Developing an Intelligent Fault Diagnosis of MF285 Tractor Gearbox Using Genetic Algorithm and Vibration Signals
}

\author{
Ebrahim Ebrahimi ${ }^{1}$, Payam Javadikia ${ }^{2}$, Nasrolah Astan ${ }^{1}$, Majid Heydari ${ }^{3}$, \\ Mojtaba Bavandpour ${ }^{1}$, Mohammad Hadi Jalili ${ }^{1}$, Ali Zarei ${ }^{4}$ \\ ${ }^{1}$ Department of Mechanical Engineering of Agricultural Machinery, Kermanshah Branch, \\ Islamic Azad University, Kermanshah, Iran \\ ${ }^{2}$ Department of Mechanical Engineering of Agricultural Machinery, Razi University, Kermanshah, Iran \\ ${ }^{3}$ Department of Mechanical Engineering of Agricultural Machinery, \\ Takestan Branch, Islamic Azad University, Takestan, Iran \\ ${ }^{4}$ Department of Mechanical Engineering of Agricultural Machinery, East Azarbaijan Sience \\ and Research Branch, Islamic Azad University, Tabriz, Iran \\ Email: e.ebrahimi57@gmail.com
}

Received August 2, 2013; revised September 19, 2013; accepted September 29, 2013

Copyright (c) 2013 Ebrahim Ebrahimi et al. This is an open access article distributed under the Creative Commons Attribution License, which permits unrestricted use, distribution, and reproduction in any medium, provided the original work is properly cited.

\begin{abstract}
This article investigates a fault detection system of MF285 Tractor gearbox empirically. After designing and constructing the laboratory set up, the vibration signals obtained using a Piezoelectric accelerometer which has been installed on the Bearing housings are related to rotary gear number 1 in two directions perpendicular to the shaft and in line with the shaft. The vector data were conducted in three different speeds of shaft 1500, 1000 and $2000 \mathrm{rpm}$ and 130 repetitions were performed for each data vector state to increase the precision of neural network by using more data. Data captured were transformed to frequency domain for analyzing and input to the neural network by Fourier transform. To do neural network analysis, significant features were selected using a genetic algorithm and compatible neural network was designed with data captured. According to the results of the best output mode for each position of the sensor network in 1000, 1500 and $2000 \mathrm{rpm}$, totally for the six output models, all function parameters for MATLAB Software quality content calculated to evaluate network performance. These experiments showed that the overall mean correlation coefficient of the network to adapt to the mechanism of defect detection and classification system is equal to $99.9 \%$.
\end{abstract}

Keywords: Fault Detection; Gearbox; Vibration Analysis; Genetic Algorithm

\section{Introduction}

Rotating machines are the mainstay of several industrial applications worldwide. They can be found in automobile, water industry, wind turbines, agricultural machinery, etc. Failures associated with gears represent the cause of extended outages and are typically caused by gradual deterioration and wear [1]. An important objective of condition-based maintenance (CBM) is to determine the optimal time for replacement or overhaul of a machine. The ability to accurately predict the remaining useful life of a machine system is crucial for its operation and can also be used to improve productivity [2]. Vibration analysis is a powerful tool in machine fault diagnosis. It is a way to check the status of a machine using a special tool. Troubleshooting machines can be more identified in the future. Fault diagnosis of mechanical or electronic components or systems is a subject of expert system applications. Today, neuro-fuzzy devices are emerged by combining network based on adaptive neural networks and fuzzy models. These adaptive networks, based on fuzzy inference system, are called ANFIS. In such systems the desired output will be achieved by means of human knowledge, in the form of if-then rules for the desired input [2]. Neuro Fuzzy system can be applied as a true model based on conventional mathematical tools and component identification. Many researchers [3-12] have employed various methods to detect weak periodic signals using the sensitivity of system parame- 
ters. Some of these methods are shock pulse monitoring, crest factor analysis, kurtosis, spectrum analysis, envelope spectrum analysis, wavelet analysis, filtration of signal, etc. Among the researches carried on machine condition monitoring with vibration analysis using fuzzy logic and neuro-fuzzy networks there are rotary machines fault diagnosis, troubleshooting automotive active suspension system and taking into account the non-linear behavior of hydraulic actuator and significantly the impaired controller, an engine control ventilation, fault diagnosis of bearing rotary, fault diagnosis of rolling bearing [13], tapered gearbox fault diagnosis [14].

In recent years, the development of mechanical equipments and maintenance has always been regarded as an essential aspect and different ways to improve safety and reduce vehicle maintenance have always been so important. On the other hand, technological advances in complicated, powerful and expensive machines caused the maintenance programs and systems to be improved [15-17]. The aim of maintenance based on the status is to gain the symbols of the industrial machinery at a time of being in progress, to provide economic and safety maintenance or to make it stay active [18-20]. Condition monitoring is performed using different techniques and methods. Each technique is particularly focused on some characteristic symptoms of the status and function of the machine and measures certain parameters that indicate the health status of the machine. Various condition monitoring techniques include vibration analysis, noise analysis, oil analysis and thermal analysis. At the technique of vibration analysis, vibration levels are measured using specific sensors [21,22]. To this end, one of the parameters of displacement velocity or acceleration would be measured. The vibration amplitude of each machine monitors the health status of this machine. Furthermore, vibration has high stability and low influence of environmental factors and since it can be an appropriate parameter for condition monitoring methods. In addition, vibration analysis can be used to troubleshoot the machine. Most problems in rotary machines are displayed as vibrating symptoms or changes in the vibration characteristics of the system. Technical advances in mechanical equipment and strong machines, machines and industrial equipment complexity and the high cost of these equipments make it necessary to develop and consider new methods of maintenance including condition monitoring. What is certain is that developing and implementing the methods for machine condition monitoring have had slower rates as a comprehensive way to maintain and troubleshoot the complex mechanical systems during the past years in developing countries which mostly rely on the imports of industrial machinery, construction, and transportation. Due to increase of the accuracy and decrease of the mistakes resulted from human judgment, today, the modeling methods are used for defects classification and detection. Regarding the considerable and increasing development in science, the older modeling and relations, more or less, have lost their influence. Besides, considering the dynamical modeling which works in various parts, caused the use of typical simple models to be complicated. The un-linearity of the problems is also an important and unignorable factor. In this regard, several modeling methods have been proposed, including ant colony, fuzzy logic theory and effective methods like artificial neural networks and genetic algorithm. Each method has its own advantages and disadvantages [2325]. In developed agriculture, it is so important to do agricultural works just on time. Time is a vital factor in agricultural systems, which could affect total function $[26,27]$. Therefore, it is necessary for the machines to be available at the time required. Whenever in Tractors of a certain farm a defect is occurred in the gear box, including the important issues that we will be encountered with, too much time and fee would be spent to transmit, open and close and repair the gear box, and since it is a vital part of the tractor and there is no more work without the gear box, so we will have to replace or repair it. However, sometimes a certain human error would cause the maintenance time and cost to be doubled. Since, for years, the experts have followed the discovery of defects in various parts of the tractor in order to reduce the time and cost of economy and raise the work efficiency. This study has been also conducted to make it easier to troubleshoot in gearbox of MF285 Tractor.

\section{Materials and Methods}

In this study a smart diagnostic system to make decisions faster than normal due to impair function machines and to increase efficiency and overall lifetime of the device is presented. After adjusting the environment settings, the test was performed in a healthy condition of gears and two defective conditions of the gear worn and the gear broken, and in three iterations of input to the axle along with installing the accelerometer sensor in both directions of Perpendicular to the axis and aligned with the axis on the bearing. For each case, the sample test was repeated 130 times and the data related to each sample were recorded and registered. In total, 2340 experimental data set were recorded as the files on Excel software and it took 20 days to collect data, as a whole. After designing and building profiles needed to position the pieces, all the necessary settings on the device and on the desktop were conducted to start the data analyzing process (Figure 1).

Once the engine rotation been measured using the optical rpm gauge, we provide different rotations in 3 various conditions and in two sensor directions in motor, implementing the dimmer, and record the relevant data. 
The gear vibrating signals are measured by the accelerometer installed on bearings on the shaft. The engine has one central axis which is coupled with the gear input and the resulted rotation speed of motor is transformed according to the proportion of the base gear. In order to make failures on gear, we used the gear with 44 gears in condition of gear 1 on the input axis (Figure 2).

In order to collect the vibrating signals, containing the healthy condition and fraction and breakage defects in both perpendicular sensor and axial sensor directions in three motor inputs 1500, 1000 and 2000 and under the loading for 4 seconds, the data were collected in all conditions. In all conditions, every 4 seconds 10,240 samples of voltage were measured in time range of 0.0004 . The software used, ARMA, recorded 10,240 voltage data in time range of 4 seconds based on the adjustments in an Excel file. After gaining the data related to healthy condition, the defects and failures considered were applied and the vibrating data were gained, separately.

\section{Signal Processing}

Signal processing and the feature extracting part are the most important parts in the condition monitoring procedure, based on which the system feature including being healthy or fractured and type of the system are de-

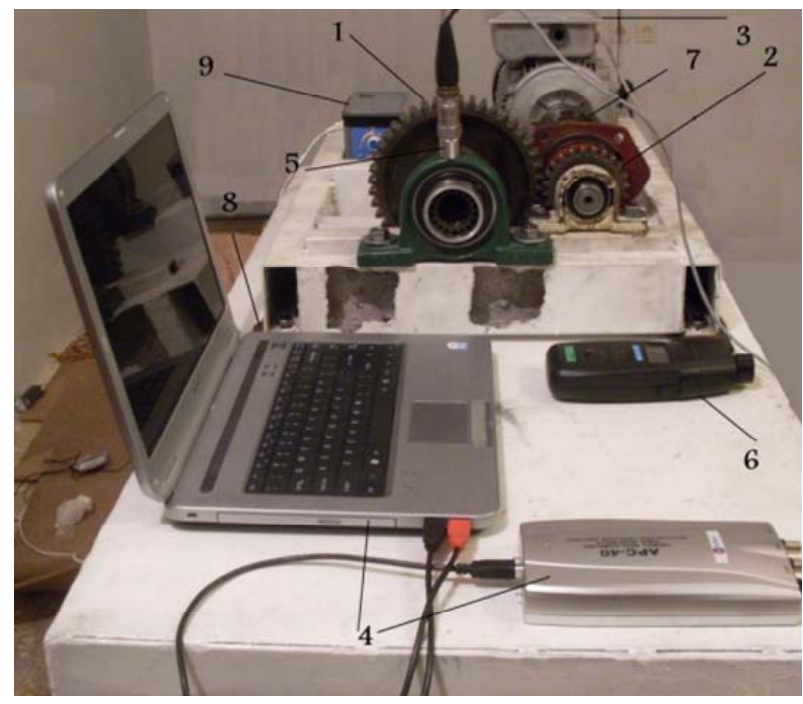

Figure 1. Gearbox set up.

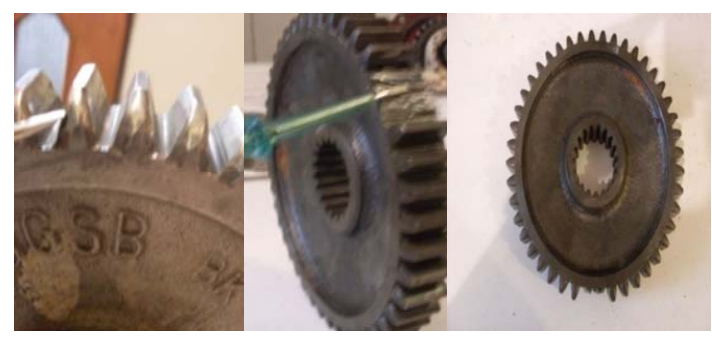

Figure 2. Broken conditions of gears. termined. The current method is to provide the sufficient features, signal transferring from time to frequency domain. For this purpose necessary codes have been transformed in the form of MATLAB software. This program selects Excel files containing the vibration data (based on time/voltage) and filters the data, eliminates the noises and finally calculated the statistical parameters of time and frequency extent, implementing the filter used. Therefore, a fast Fourier function (FFF) of 10,240 points was calculated for each time signal, separately. Also, the power spectral density (PSD) and phase angle (FFT) of vibration signals were calculated using the software MATLAB.

\section{Feature Extraction}

The main aim in feature extraction methods is to provide a way or arrangement that could monitor the components hidden in a signal. In this study, 10,240 data sample from time extent formed the data collection. Also, the frequency extent data points, let's say PSD and phase angel FFT, were each 10,240 . These signals were used to extract 33 features of healthy and failure conditions. 11 features (T1 - T11) were from statistical parameters in time extent and the remaining (P1 - P11) and (A1 - A11) were from statistical parameters in frequency extent (Table 1).

Then, using MATLAB software, the diagrams related to vibration spectrum in frequency extent in healthy and failure conditions were gained due to get analyzed and compared to each other. In order to make the differences in the frequency of normal and defective devices more clear, either axial rotation $1000 \mathrm{rpm}$ and $2000 \mathrm{rpm}$ on the two healthy gear broken at the same diagrams were classified (Figure 3).

Figure 3 shows that in safety condition in both 1000 and $2000 \mathrm{rpm}$, the amplitude for each diagram remains unchanged during the work and only one or two cases have a maximum that could be justifiable due to the gear involvement. But in unhealthy conditions while the gear with broken gear is replaced with the safe one, the frequency-voltage diagram will immediately have many maximum points which are occurred almost in a regular order. It could be observed that in increasing the rotary axis rotation there are some fixed amplitude increase, while in the broken gear the increase in amplitude is iterated in an unusual way in certain coefficients. The difference resulted from the broken gear has been illustrated in frequency-voltage diagrams against the time-voltage diagram.

\section{Classification of Defects}

In MATLAB software using the neural network, the chromosomal genetic with 20 gens was designed and the 
Table 1. Features of time and frequency domain.

\begin{tabular}{|c|c|c|}
\hline \multicolumn{2}{|c|}{ Frequency extent features } & \multirow{2}{*}{ Time extent features } \\
\hline phase angel FFT & PSD & \\
\hline$A_{1}=\frac{\sum_{j-1}^{J} i(j)}{J}$ & $\mathrm{P}_{1}=\frac{\sum_{\mathrm{K}-1}^{\mathrm{K}} \mathrm{s}(\mathrm{k})}{\mathrm{K}}$ & $\mathrm{T}_{1}=\frac{\sum_{\mathrm{n}-1}^{\mathrm{N}} \mathrm{x}(\mathrm{n})}{\mathrm{N}}$ \\
\hline$A_{2}=\sqrt{\frac{\sum_{j-1}^{J}\left(i(j)-A_{1}\right)^{2}}{J-1}}$ & $\mathrm{P}_{2}=\sqrt{\frac{\sum_{\mathrm{K}-1}^{\mathrm{K}}\left(\mathrm{s}(\mathrm{k})-\mathrm{P}_{1}\right)^{2}}{\mathrm{k}-1}}$ & $\mathrm{~T}_{2}=\sqrt{\frac{\sum_{\mathrm{n}-1}^{\mathrm{N}}(\mathrm{x}(\mathrm{n})-\mathrm{T} 1)^{2}}{\mathrm{~N}-1}}$ \\
\hline$A_{3}=\sqrt{\frac{\sum_{j-1}^{J}(i(j))^{2}}{J}}$ & $\mathrm{P}_{3}=\sqrt{\frac{\sum_{\mathrm{K}-1}^{\mathrm{K}}(\mathrm{s}(\mathrm{k}))^{2}}{\mathrm{~K}}}$ & $\mathrm{~T}_{3}=\sqrt{\frac{\sum_{\mathrm{n}-1}^{\mathrm{N}}(\mathrm{x}(\mathrm{n}))^{2}}{\mathrm{~N}}}$ \\
\hline $\mathrm{P}_{4}=\max |\mathrm{i}(\mathrm{j})|$ & $\mathrm{P}_{4}=\max |\mathrm{s}(\mathrm{k})|$ & $\mathrm{T}_{4}=\max |\mathrm{x}(\mathrm{n})|$ \\
\hline$A_{5}=\frac{A_{3}}{\frac{1}{J} \sum_{j-1}^{J}|s(j)|}$ & $\mathrm{P}_{5}=\frac{\mathrm{P}_{3}}{\frac{1}{\mathrm{~K}} \sum_{\mathrm{k}-1}^{\mathrm{K}}|\mathrm{S}(\mathrm{k})|}$ & $\mathrm{T}_{5}=\frac{\mathrm{T}_{3}}{\frac{1}{\mathrm{~N}} \sum_{\mathrm{n}-1}^{\mathrm{N}}|\mathrm{x}(\mathrm{n})|}$ \\
\hline$A_{6}=\frac{A_{4}}{\frac{1}{J} \sum_{j-1}^{J}|s(j)|}$ & $\mathrm{P}_{6}=\frac{\mathrm{P}_{4}}{\frac{1}{\mathrm{~K}} \sum_{\mathrm{k}-1}^{\mathrm{K}}|\mathrm{s}(\mathrm{k})|}$ & $\mathrm{T}_{6}=\frac{\mathrm{T}_{4}}{\frac{1}{\mathrm{~N}} \sum_{\mathrm{n}-1}^{\mathrm{N}}|\mathrm{x}(\mathrm{n})|}$ \\
\hline $\mathrm{A}_{7}=\frac{\mathrm{A}_{4}}{\mathrm{~A}_{3}}$ & $\mathrm{P}_{7}=\frac{\mathrm{P}_{4}}{\mathrm{P}_{3}}$ & $\mathrm{~T}_{7}=\frac{\mathrm{T}_{4}}{\mathrm{~T}_{3}}$ \\
\hline$A_{8}=\sqrt{\frac{j \sum_{j-1}^{J} i^{2}(j)-\sum_{j-1}^{J}(i(j))^{2}}{j(j-1)}}$ & $\mathrm{P}_{\mathrm{g}}=\sqrt{\frac{\mathrm{K} \sum_{\mathrm{k}-1}^{\mathrm{K}} \mathrm{s}^{2}(\mathrm{k})-\sum_{\mathrm{k}-1}^{\mathrm{K}}(\mathrm{s}(\mathrm{k}))^{2}}{\mathrm{k}(\mathrm{k}-1)}}$ & $\mathrm{T}_{8}=\sqrt{\frac{\mathrm{n} \sum_{\mathrm{n}-1}^{N} \mathrm{x}^{2}(\mathrm{n})-\sum_{\mathrm{n}-1}^{N}(\mathrm{x}(\mathrm{n}))^{2}}{\mathrm{n}(\mathrm{n}-1)}}$ \\
\hline $\mathrm{A}_{9}=\left(\mathrm{A}_{8}\right)^{2}$ & $\mathrm{P}_{9}=\left(\mathrm{P}_{8}\right)^{2}$ & $\mathrm{~T}_{9}=\left(\mathrm{T}_{8}\right)^{2}$ \\
\hline$A_{10}=\frac{\sum_{j-1}^{J}\left(i(j)-A_{1}\right)^{4}}{J \times\left(A_{9}\right)^{2}}$ & $\mathrm{P}_{10}=\frac{\sum_{\mathrm{k}-1}^{\mathrm{K}}\left(\mathrm{s}(\mathrm{k})-\mathrm{P}_{1}\right)^{4}}{\mathrm{~K} \times\left(\mathrm{P}_{9}\right)^{2}}$ & $\mathrm{~T}_{10}=\frac{\sum_{\mathrm{n}-1}^{\mathrm{N}}\left(\mathrm{x}(\mathrm{n})-\mathrm{T}_{1}\right)^{4}}{\mathrm{~N} \times\left(\mathrm{T}_{9}\right)^{2}}$ \\
\hline$A_{11}=\frac{j}{(j-1)(j-2)} \sum_{j-1}^{j}\left(\frac{i(j)-A_{1}}{A_{8}}\right)^{3}$ & $\mathrm{P}_{11}=\frac{\mathrm{k}}{(\mathrm{k}-1)(\mathrm{k}-2)} \sum_{\mathrm{k}-1}^{\mathrm{K}}\left(\frac{\mathrm{s}(\mathrm{k})-\mathrm{P}_{1}}{\mathrm{P}_{8}}\right)^{3}$ & $\mathrm{~T}_{11}=\frac{\mathrm{n}}{(\mathrm{n}-1)(\mathrm{n}-2)} \sum_{\mathrm{n}-1}^{\mathrm{N}}\left(\frac{\mathrm{x}(\mathrm{n})-\mathrm{T}_{1}}{\mathrm{~T}_{8}}\right)$ \\
\hline $\begin{array}{c}\text { In which } \mathrm{i}(\mathrm{j}) \text { is a signal } \\
\text { for } \mathrm{j}=1,2, \ldots \text {, J. } \\
\mathrm{J} \text { indicates the number of data points. }\end{array}$ & $\begin{array}{l}\text { in which } \mathrm{s}(\mathrm{k}) \text { is a signal } \\
\text { for } \mathrm{k}=1,2, \ldots, \mathrm{K} \text {. } \\
\mathrm{K} \text { indicates the number } \\
\text { of data points. }\end{array}$ & $\begin{array}{l}\text { in which } \mathrm{x}(\mathrm{n}) \text { is a signal } \\
\text { for } \mathrm{n}=1,2, \ldots, \mathrm{N} \text {. } \\
\mathrm{N} \text { indicates the number } \\
\text { of data points. }\end{array}$ \\
\hline
\end{tabular}

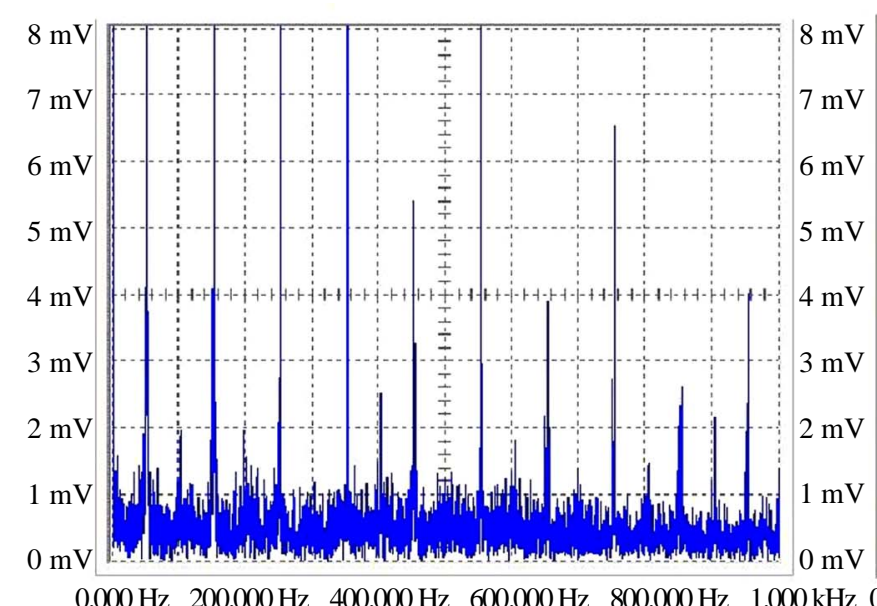

(a)

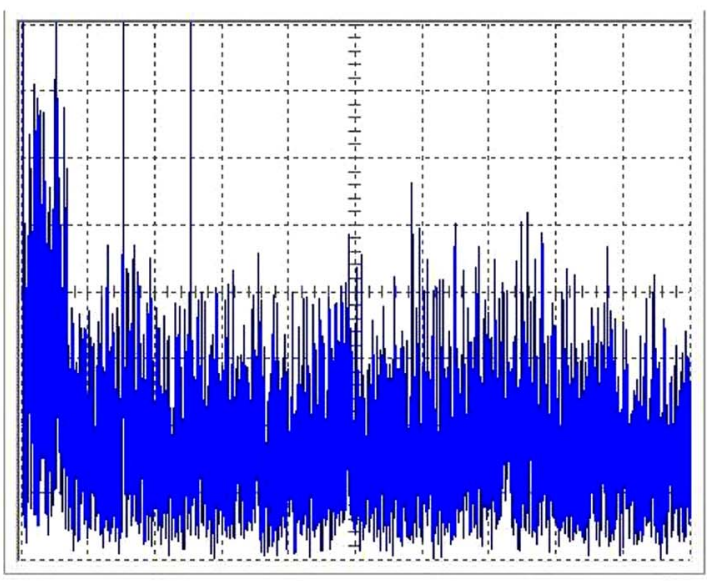

(b)

Figure 3. FFT diagram of (a) healthy condition (b) fault condition.

proper neural network structure was created by determining the number of layers, neurons, epoxies, biases and gens implementing the numbered gens capacity, which studied using various statistical parameters of effi- 
ciency and error percent of neural network structure. Applying the genetic-neural network hybrid, the necessary classification and calculations were performed to create a network compatible with the test. In this study, one chromosome with 20 gens was designed. The first gen determines the number of inputs. Because, it was tried to investigate each input parameter on the model output and if any of these inputs have trivial impact on the model output it would be deleted from the model and in other words the unvalued inputs genetic algorithm will be eliminated (Figure 4).

Gens 2 and 9 illustrate two considerable issues from the neural network structure, one shows the number of layers hidden in network and the other illustrates the number of neurons in each hidden layer, and the amount could be variable from 0 to 12 . The transfer functions include: competitive functions, two-valued stimulation threshold, two-valued symmetrical stimulation threshold, sigmoid, converse, positive linear, linear, radial, saturated linear, symmetrical saturated linear, triangular and sigmoid hyperbolic tangent. The 18th gen determined the type of training function, and the amount of this gen could be variable from 0 to 18 . The training functions include: the combined gradient algorithm Powell Beale, the combined gradient algorithm Polak-Ribirere, Resilient Back propagation, BFGS algorithm, One Step Secant

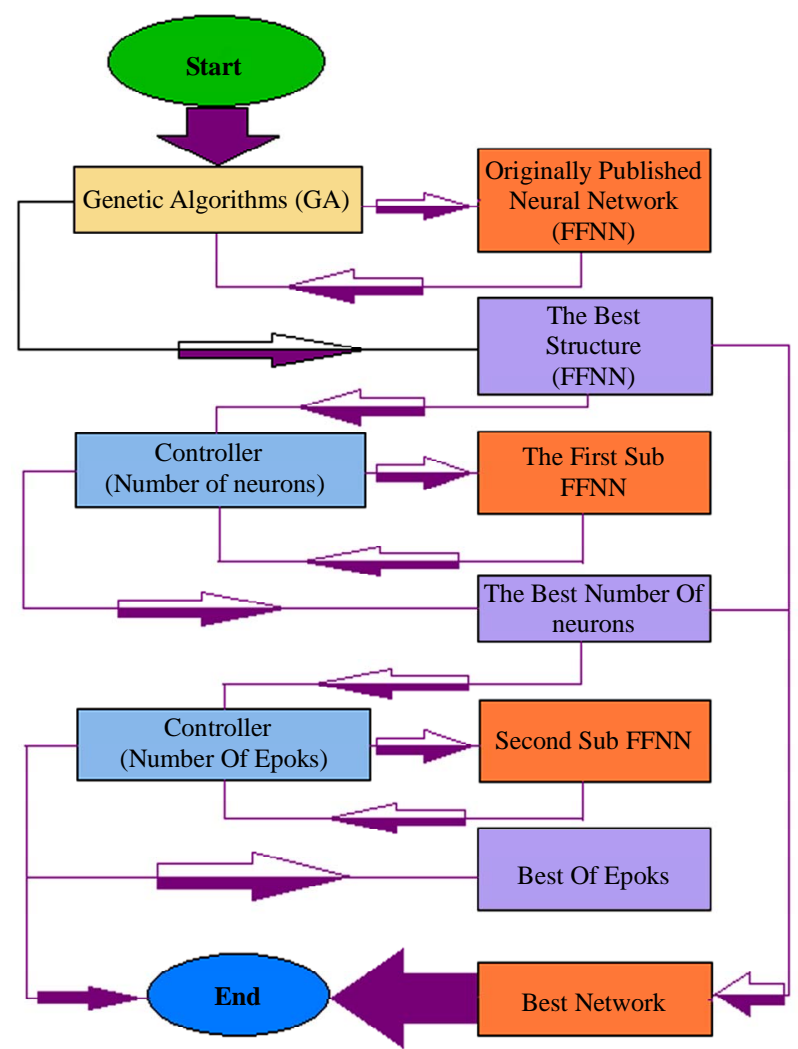

Figure 4. A sample of genetic algorithm structure and procedure to form the best neural network. algorithm, Levenberg-Marquardt algorithm, the scaled combined gradient algorithm, quasi-Newton back propagation algorithm, monomentum algorithm, combined gradient algorithm Flathcher-Reeves and etc. the 19th gen determines the learning function that have the range of 0 to 14. The learning functions include: bias reduction, weigh or bias of descent gradient, the descent gradient with Monomentum weigh or bias, weigh given, the rule of learning hob with descent weigh, the Instar weigh, the Kohnen weigh, the vector quantization learning weigh LVQ1, LVQ2, outstar weigh, percepteron weigh and bias, percepteron normalized weigh and bias, self-organizer mapping weigh, collective self-organizer mapping weigh and the rule of Vidro-Hauf weigh and bias learning. The 20st gen determines the epoxies to train each network and the range is variable from 10 to 500 . Regarding the genetic algorithm adjustments, the best population number for each generation was selected as 50 . So, the scale of terminating the genetic algorithm was selected as 100 and the competitive method and two-pointed integration were implemented. All data were included 30 percent of test and 70 percent of training and all the calculations were performed by hybrid genetic-neural network. The optimizing program was used in software MATLAB version Release 2010a, as a whole. In order to classify and analyze the failures and relevant parameters, using the neural network and gaining effective and necessary inputs to be applied in neural-genetic network, the nerve solution was implemented. This software is a sort of developed environment for neural networks, which includes the models based on network design, implementation using advanced learning methods like conjugate gradient, Lonberg-Marquadet and the error propagation during the time. This designing, training and establishing the neural networks (learning under supervision and training without supervision), is used to perform an extent range of tasks like: data analysis, classification, multi-variable regression and time series prediction. Implementing the nerve solution software sensitivity analysis the considered inputs from 55 inputs we had calculated, were gained and the analysis diagram of sensitivity to the average for all data related to the condition of perpendicular to shaft at $1000 \mathrm{rpm}$ was drawn .According to previous analysis using MATLAB for which the results were recorded as the same names in different columns in Excel files, the name of each column is significant for the next calculation. Implementing the name of these variables, the relevant addresses were used as the neural network inputs (Table 2), and then using genetic algorithm in software MATLAB, the best designing structure and it's features were registered (Table 3).

\section{Result}

To evaluate the accuracy of the neural network model, 
Table 2. Features of selected inputs for neural network models.

\begin{tabular}{ccc}
\hline inputs & models & Number \\
\hline psd-value-y-FFT phase angle-y & Perpendicular-1000 rpm & $\mathbf{1}$ \\
fft-values-FFT phase angle-psd-value & Perpendicular-1500 rpm & $\mathbf{2}$ \\
psd-value-fft-values-fft-values-y-psd-value & Perpendicular to the axis at 2000 rpm & $\mathbf{3}$ \\
fft-values-psd-value-FFT phase angle-y & Aligned with the axis at 1000 rpm & $\mathbf{5}$ \\
psd-value-psd-value-y-FFT phase angle-y & Aligned with the axis at $1500 \mathrm{rpm}$ & $\mathbf{6}$ \\
FFT phase phase-FFT phase angle-fft-values & Aligned with the axis at 2000 rpm &
\end{tabular}

Table 3. Neural network, designed and optimized using genetic algorithm.

\begin{tabular}{|c|c|c|c|c|c|c|c|c|c|}
\hline \multirow{2}{*}{$\begin{array}{l}\text { Number } \\
\text { of epoks }\end{array}$} & \multirow{2}{*}{$\begin{array}{l}\text { Quality } \\
\text { function }\end{array}$} & \multirow{2}{*}{$\begin{array}{l}\text { bias/weigh } \\
\text { training function }\end{array}$} & \multirow{2}{*}{$\begin{array}{l}\text { network training } \\
\text { function }\end{array}$} & \multicolumn{2}{|c|}{ output layers } & \multicolumn{2}{|c|}{ hidden layers } & \multirow{2}{*}{$\begin{array}{l}\text { No. of } \\
\text { inputs }\end{array}$} & \multirow{2}{*}{$\begin{array}{l}\text { Neural network, } \\
\text { designed and } \\
\text { optimized using } \\
\text { genetic algorithm }\end{array}$} \\
\hline & & & & transfer function & $\begin{array}{l}\text { No. of } \\
\text { neurons }\end{array}$ & transfer function & $\begin{array}{l}\text { No. of } \\
\text { neurons }\end{array}$ & & \\
\hline 287 & $\begin{array}{c}\text { the mean } \\
\text { square error }\end{array}$ & $\begin{array}{c}\text { descent gradient } \\
\text { with monomentum } \\
\text { weigh or bias }\end{array}$ & $\begin{array}{c}\text { Lonberg-Marquidet } \\
\text { back propagation }\end{array}$ & $\begin{array}{l}\text { Hyperbolic } \\
\text { tangent } \\
\text { sigmoid }\end{array}$ & 1 & $\begin{array}{l}\text { Hyperbolic } \\
\text { tangent } \\
\text { sigmoid }\end{array}$ & 5 & 4 & 1 \\
\hline 143 & $\begin{array}{c}\text { the mean } \\
\text { square error }\end{array}$ & $\begin{array}{c}\text { descent gradient } \\
\text { with monomentum } \\
\text { weigh or bias }\end{array}$ & $\begin{array}{c}\text { Lonberg-Marquidet } \\
\text { back propagation }\end{array}$ & $\begin{array}{l}\text { Hyperbolic } \\
\text { tangent } \\
\text { sigmoid }\end{array}$ & 1 & $\begin{array}{l}\text { Hyperbolic } \\
\text { tangent } \\
\text { sigmoid }\end{array}$ & 12 & 3 & 2 \\
\hline 82 & $\begin{array}{c}\text { the mean } \\
\text { square error }\end{array}$ & $\begin{array}{c}\text { descent gradient } \\
\text { with monomentum } \\
\text { weigh or bias }\end{array}$ & $\begin{array}{c}\text { Lonberg-Marquidet } \\
\text { back propagation }\end{array}$ & $\begin{array}{c}\text { Hyperbolic } \\
\text { tangent } \\
\text { sigmoid }\end{array}$ & 1 & $\begin{array}{l}\text { Hyperbolic } \\
\text { tangent } \\
\text { sigmoid }\end{array}$ & 9 & 5 & 3 \\
\hline 272 & $\begin{array}{c}\text { the mean } \\
\text { square error }\end{array}$ & $\begin{array}{c}\text { descent gradient } \\
\text { with monomentum } \\
\text { weigh or bias }\end{array}$ & $\begin{array}{c}\text { Lonberg-Marquidet } \\
\text { back propagation }\end{array}$ & $\begin{array}{c}\text { Hyperbolic } \\
\text { tangent } \\
\text { sigmoid }\end{array}$ & 1 & $\begin{array}{l}\text { Hyperbolic } \\
\text { tangent } \\
\text { sigmoid }\end{array}$ & 7 & 4 & 4 \\
\hline 251 & $\begin{array}{c}\text { the mean } \\
\text { square error }\end{array}$ & $\begin{array}{c}\text { descent gradient } \\
\text { with monomentum } \\
\text { weigh or bias }\end{array}$ & $\begin{array}{c}\text { Lonberg-Marquidet } \\
\text { back propagation }\end{array}$ & $\begin{array}{c}\text { Hyperbolic } \\
\text { tangent } \\
\text { sigmoid }\end{array}$ & 1 & $\begin{array}{c}\text { Hyperbolic } \\
\text { tangent } \\
\text { sigmoid }\end{array}$ & 8 & 5 & 5 \\
\hline 146 & $\begin{array}{c}\text { the mean } \\
\text { square error }\end{array}$ & $\begin{array}{c}\text { descent gradient } \\
\text { with monomentum } \\
\text { weigh or bias }\end{array}$ & $\begin{array}{c}\text { newton back } \\
\text { propagation network }\end{array}$ & $\begin{array}{l}\text { Hyperbolic } \\
\text { tangent } \\
\text { sigmoid }\end{array}$ & 1 & $\begin{array}{l}\text { Hyperbolic } \\
\text { tangent } \\
\text { sigmoid }\end{array}$ & $14^{*} 1^{*} 1$ & 3 & 6 \\
\hline
\end{tabular}

the data collection in training and test sets were analyzed statistically based on features extracted from the network. MATLAB software was used to perform classification. Statistical parameters such as mean-square error (MSE), Mean-square normalized error (MSNE) and multi-layer network error were compared (Figures 5 and 6), (Table 4). The best network outputs for each sensor condition are divided into three 1000, 1500 and $2000 \mathrm{rpm}$. There are, totally, 6 output models for which all the system function statistical parameters have been calculated (Table 4). Due to compare two diagnostic positions of each model, general description of the correlation coefficient in each case is given in diagram (Figure 7). The highest correlation coefficients in Model 4 and 5 are about 99\% and the lowest one in model (6) is about $97 \%$.

\section{Conclusion}

In this study a network-compatible device has been designed using artificial neural networks, to detect and classify defects in a Massey Ferguson 285 tractor gear. According to the results, the best network outputs for each sensor mode are divided into three categories in 1000 , 1500 and $2000 \mathrm{rpm}$. Totally, outputs for six cases and the function of all the quality parameters have been computed in order to troubleshoot the gear 1 for gear box in tractor Massey Ferguson 285 in the worst case (aligned with the axis at $2000 \mathrm{rpm}$ ) with a correlation coefficient of $97 \%$ and the mean square error of $0.000047 \%$. The numbers indicate the high accuracy and low error in trial, respectively. These experiments showed that the overall 

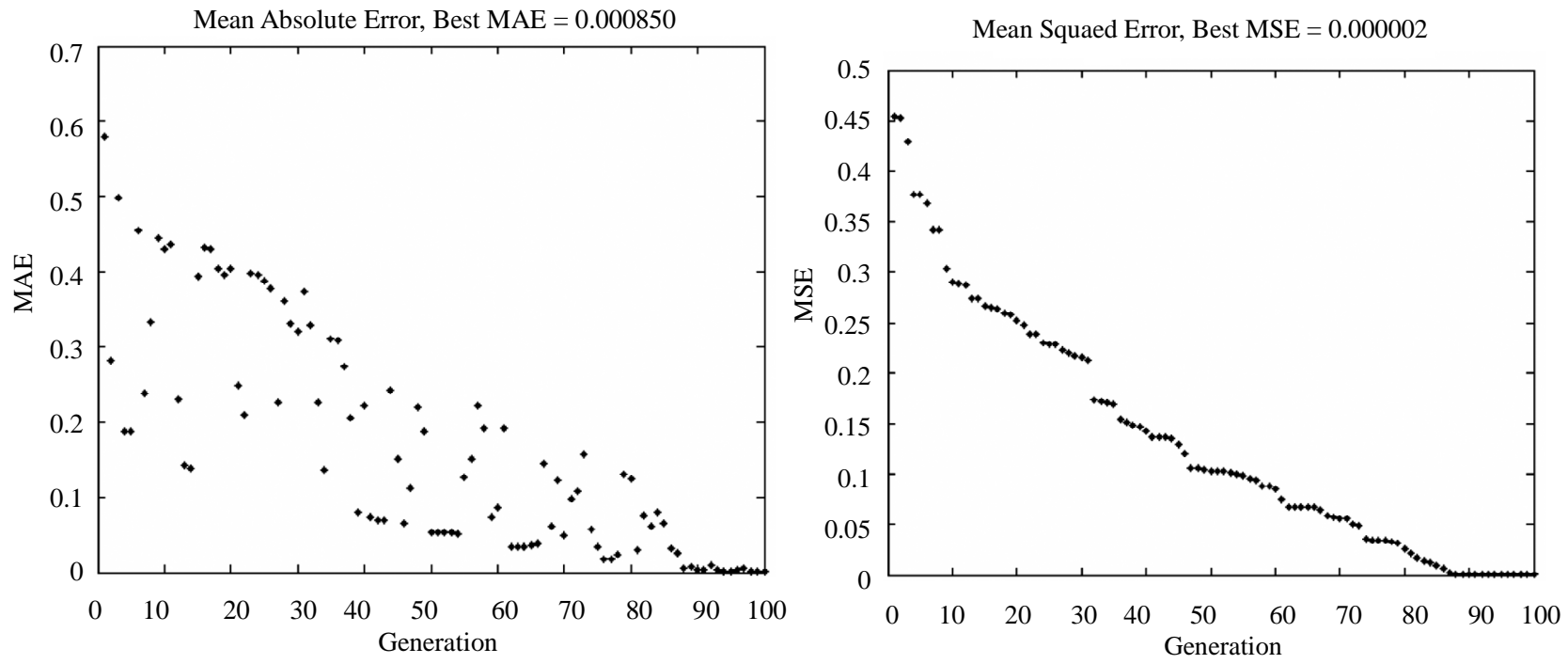

Figure 5. Mean-square error network output results at $1000 \mathrm{rpm}$ in the status of perpendicular on the axis.

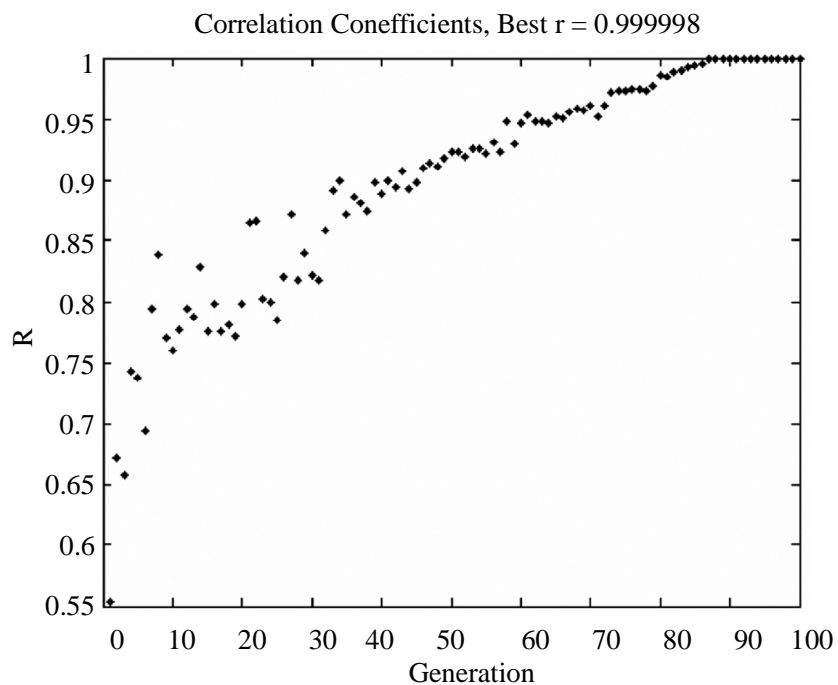

Mean Squared Normalized Error, BEST MSNE $=0.000002$

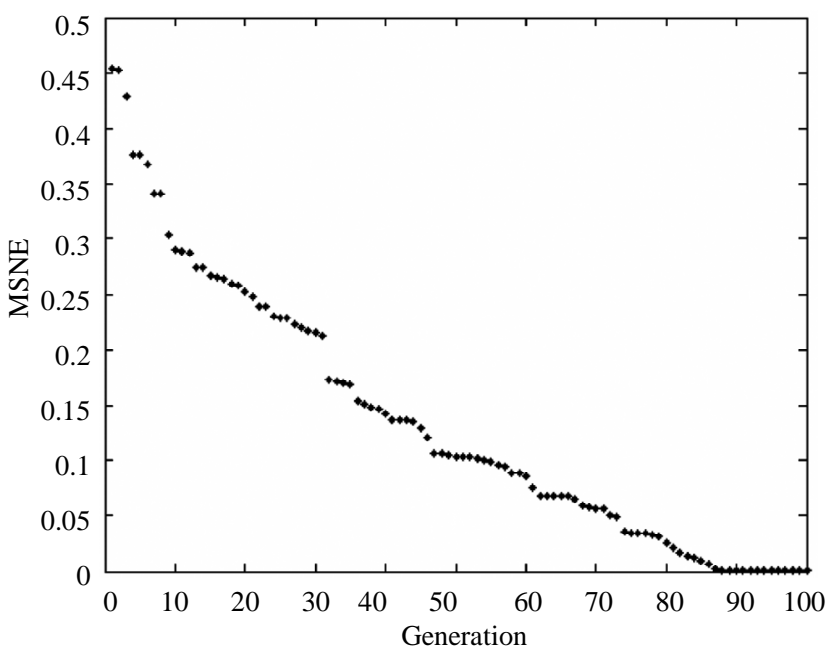

Figure 6. Mean-square normalized error and the correlation coefficient in network output results at 1000 rpm in the status of perpendicular on the axis.

Table 4. The best network results gained in graphs.

\begin{tabular}{|c|c|c|c|c|c|}
\hline correlation coefficient (r) & $\begin{array}{l}\text { mean absolute error } \\
\text { (MAE) }\end{array}$ & $\begin{array}{l}\text { Mean-square normalized } \\
\text { error (MSNE) }\end{array}$ & $\begin{array}{l}\text { mean-square error } \\
\text { (MSE) }\end{array}$ & $\begin{array}{l}\text { The best network design } \\
\text { using genetic algorithm }\end{array}$ & NO \\
\hline 0.999998 & 0.000850 & 0.000002 & 0.000002 & $\begin{array}{l}\text { perpendicular on the } \\
\text { axis at } 1000 \mathrm{rpm}\end{array}$ & 1 \\
\hline 0.999998 & 0.001442 & 0.000004 & 0.000004 & $\begin{array}{l}\text { perpendicular on the } \\
\text { axis at } 1500 \mathrm{rpm}\end{array}$ & 2 \\
\hline 0.999998 & 0.001442 & 0.000006 & 0.000006 & $\begin{array}{l}\text { perpendicular on the } \\
\text { axis at } 2000 \mathrm{rpm}\end{array}$ & 3 \\
\hline 0.999999 & 0.000147 & 0.000001 & 0.000001 & $\begin{array}{l}\text { aligned with the } \\
\text { axis at } 1000 \text { rpm axis at }\end{array}$ & 4 \\
\hline 0.999999 & 0.000207 & 0.000001 & 0.000001 & $\begin{array}{l}\text { aligned with the } \\
\text { axis at } 1500 \mathrm{rpm}\end{array}$ & 5 \\
\hline 0.999979 & 0.004012 & 0.000047 & 0.000047 & $\begin{array}{l}\text { aligned with the } \\
\text { axis at } 2000 \text { rpm }\end{array}$ & 6 \\
\hline
\end{tabular}




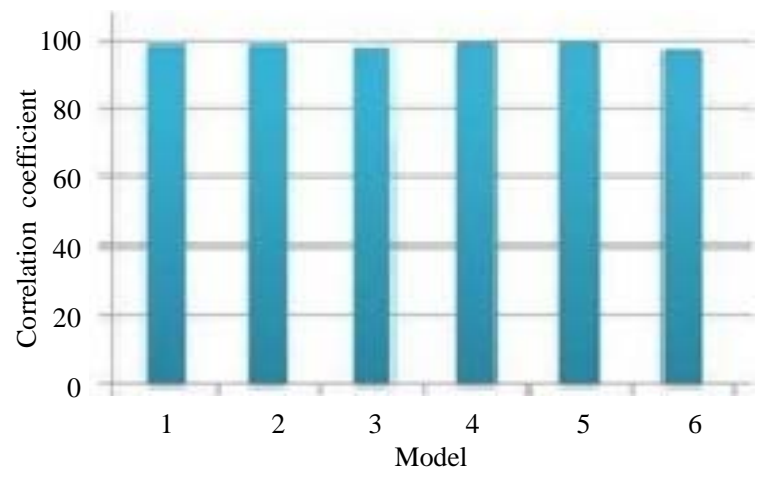

Figure 7. The overall correlation diagram based on tested models.

mean correlation coefficient of the network is equal to $99 \%$, to adapt to the mechanism of defect detection and classification system, and according to the definition of correlation coefficient, this number is near 1 that is the desired mode and the mean error occurred in defect detection is nearly 0 . These statistical results show the efficiency and applicability of this method to detect the defects in gearbox.

\section{Acknowledgements}

The authors would like to thank Islamic Azad University, Kermanshah Branch for its support to this research.

\section{REFERENCES}

[1] M. Elforjani, D. Mba, A. Muhammad and A. Sire "Condition Monitoring of Worm Gears," Applied Acoustics, Vol. 73 No. 8, 2012, pp. 859-863. http://dx.doi.org/10.1016/j.apacoust.2012.03.008

[2] H.-E. Kim, A. C. C. Tan, J. Mathew and B.-K. Choi, "Bearing Fault Prognosis Based on Health State Probability Estimation,” Expert Systems with Applications, Vol. 39, No. 5, 2012, pp. 5200-5213.

http://dx.doi.org/10.1016/j.eswa.2011.11.019

[3] P. J. Dempsey, D. G. Lewicki, and H. J. Decker, “Decker Transmission Bearing Damage Detection Using Decision Fusion Analysis," Glenn Research Center, Cleveland, Army Research Laboratory, NASA/TM, 2004, pp. 1-20.

[4] G. Goddu, B. Li, M. Chow and J. Hung, "Motor Bearing Fault Diagnosis by Fundamental Frequency Amplitude Based Fuzzy Decision System,” North Carolina University. 1998, pp. 1961-1965.

[5] N. Hotwai, "Vibration Analysis of Faulty Beam usig Fuzzy Logic Techique,” BTech Thesis, National Institute of Technology, Rourkela, 2009, pp. 23-27.

[6] Ch. Kong, J. Ki, S. Oh and J. Kim, “Trend Monitoring of a Turbofan Engine for Long Endurance UAV Using Fuzzy Logic,” KSAS Enternational Gournal, Vol. 9. 2008, pp. 64-70.

[7] Z. Kiral and H. Karagulle, "Simulation and Analysis of Vibration Signals Generated by Rolling Element Bearing with Defects,” Tribology International, Vol. 36, No. 9, 2003, pp. 667-678.

[8] Y. G. Lei, Z. J. He and Y. Y. Zi and X. Hu, "Fault Diagnosis of Rotating Machinery Based on Multiple ANFIS Combination with Gas," Mechanical Systems and Signal Processing, Vol. 21, No. 5, 2007, pp. 2280-2294.

[9] Y. G. Lei, Z. J. He and Y. Y. Zi, "A New Approach to Intelligent Fault Diagnosis of Rotating Machinery," Expert Systems with Applications, Vol. 35, No. 4, 2008, pp. 1593-1600.

[10] R. Martins Marcal, K. Hatakeyama and A. Susin, "Managing Incipient Faults in Rotating Machines Based on Vibration Analysis and Fuzzy Logic,” Electrical Engineering Department, 2006, pp. 1-6.

[11] N. Saravanan, S. Cholairajan and K. I. Ramachandran "Vibration-based Fault Diagnosis of Spur Bevel Gear box Using Fuzzy Technique,” Expert Systems with Applications, Vol. 36, No. 2, 2009, pp. 3119-3135.

[12] T. I. Liua, J. H. Singonahallib and N. R. Iyerb, "Detection of Roller Bearing Defect Using Expert System and Fuzzy Logic,” Mechanical Systems and Signal Processing, Vol. 10, No. 5, 1996, pp. 595-614.

[13] E. Ebrahimi and K. Mollazade, "Intelligent Fault Classification of a Tractor Starter Motor Using Vibration Monitoring and Adaptive Neuro-Fuzzy Inference System," Insight-Non-Destructive Testing and Condition Monitoring, Vol. 52, No. 10, 2010, pp. 561-566.

[14] G. H. Payganeh, M. N. Khajavi, R. Ebrahimpour, and E. Babaei, "Troubleshooting of Rotating Machines Using Neural Networks," 6th National Conference on Maintenance and Repair, Tehran, Iran.

[15] A. Bavi and M. Salehi, "Genetic Algorithms and Optimization of Composite Structures,” Tehran, Abed.

[16] D. Boostan and N. Pariz, “Analysis of Vibration Signals Using Short Time Fourier Transform, Neural Networks and Fuzzy Inference to Identify the Type and Severity of Damage in the Bearing," 16th Annual International Conference on Mechanical Engineering, Tehran, Shahid Bahonar University.

[17] M. Behzad, K. Sepanloo, M. Asayesh and E. Rohani, "Fundamentals of Vibrations in the Maintenance, Repair and Troubleshooting of Rotating Machinery,” NPC Publication.

[18] H. Beigy, "MF 285 Vibrating Gearbox Condition Monitoring and Fault Features and Its Classification Using Artificial Neural Networks,” M.Sc. Thesis, Tehran University.

[19] E. Rohani, M. Alikhani, E. Mostafavi Manesh, M. R. Darbandi and M. E. A. Behzad, "Troubleshooting by the Help of Turbo Compressors Gas Pipeline Vibration Analysis, Condition Monitoring and Diagnostics of Machines," 4th Conference of Iran, Sharif University of Technology, Tehran.

[20] M. Ryahi and A. Tarbareh, "Designing and Manufacturing the System of Information Recording and Preserving on Heavy Machinery to Monitor and Analyze the Status, Condition Monitoring and Diagnostics of Machines," 4th Conference of Iran, Sharif University of 
Technology, Tehran.

[21] B. V. Zahraei and M. Hosseyni, "Genetic Algorithms and Engineering Optimization,” Tehran, Gothenbur.

[22] M. Shakeri and M. Nozad, "Remote Diagnostics of Rotating Machineries Based on Vibration Condition Monitoring and Troubleshooting of Machines," 4th Technical Conference and Equipment of Iran, Sharif University of Technology, Tehran.

[23] E. Ghafar Nejad Mehraban and M. Homayoon Sadeghi, "Smart Troubleshooting for Car Gearbox Vibration Using Analysis and Artificial Neural Networks by Analyzing Violet," 16th Annual Conference on Mechanical Engineering.

[24] A. Farshidian Far, S. Maleki and E. Andakhshideh, "Vortex-Induced Vibration Modeling and Optimization of
Cylinders by a Neural Network and Genetic Algorithm," 7th Annual Conference of the International Association of Aerospace Iran, Sharif University of Technology, Tehran.

[25] M. Kia, “Neural networks in Matlab,” Kian Publication of Rayaneh Sabz, Tehran.

[26] H. Mohammadi Monavar, "Vibration Condition Monitoring in Agriculture Electro-Motors with Fans,” Master's Thesis, Tehran University, Tehran.

[27] K. MollaZadeh, "Vibration Condition Monitoring of Hydraulic Steering Pump MF 285 and the Defects Classification Using Fuzzy Logic,” Master's Thesis, Tehran University, Tehran. 